\title{
THE DEVELOPMENT OF ALTERNATIVE METHOD OF COATING OF SLIDING SURFACE ON HYDRODYNAMIC BEARING BY THERMAL SPRAYING AND LASER CLADDING
}

\author{
${ }^{1}$ Petra FRKOVÁ, 2̌̌árka HOUDKOVÁ, ${ }^{3}$ Marek VOSTŘÁK, ${ }^{4}$ Jiří HALML \\ ${ }^{1,2}$ Research and Testing Institute Pilsen, Pilsen, Czech Republic, EU, \\ 1frkova@vzuplzen.cz, ${ }^{2}$ houdkova@vzuplzen.cz \\ ${ }^{3}$ University of West Bohemia New Technologies - Research Centre, Pilsen, Czech Republic, EU, \\ mvostrak@ntc.zcu.cz \\ ${ }^{4}$ GTW Bearings, Přišov, Czech Republic, EU, jhalml@gtw.cz
}

https://doi.org/10.37904/metal.2019.733

\begin{abstract}
The main factor for operating characteristics of sliding bearing is a quality of the lining surface. For low friction and better functionality, the coating of sliding surface is commonly used. The material of coating is usually alloys based on tin or copper. The main methods of coating application of these materials are centrifugal and static casting. The adhesion of such lining is based on the diffusion of tin into steel substrate. In production, the usage of casting technology is limited by proportions and weight of bearings. As alternative technologies of bearing lining deposition, the technologies of thermal spraying and laser cladding can be suggested. In the paper, the first phase of this study is described. The coating was applied by flame spraying, arc spraying and by laser cladding. The materials are tin composition, called also Babbitt, and aluminum bronze. The effect of spray parameters was investigated and the optimal parameters for the spraying were searched. Basic characteristics of the coating, such a microstructure, hardness, surface roughness and adhesion, were tested. Real applicability of coating has also been evaluated. All these technologies were found suitable for deposition of bearing linings with satisfactory microstructural and mechanical characteristics. Such coating could be suitable for hard-working bearing where long-life is required.
\end{abstract}

Keywords: Thermal spraying, laser cladding, sliding bearing, coating

\section{INTRODUCTION}

The hydrodynamic bearings made by GTW Bearings are commonly manufactured with lining based on tin or cooper alloys. This lining improves the sliding properties, functionality and significantly extends the service life of the bearings. The quality of the lining strongly affects the quality of the bearings. The main methods of application of these materials to the bearings are centrifugal and static casting. The adhesion between the lining and substrate is based on the diffusion of tin or cooper into a steel substrate. These methods are mostly limited by proportions and weight of bearings. These processes are also very demanding in terms of energy, time and cost. [1]

The purpose of project called "A New generation of hydrodynamic bearings with lining applicated by thermal spraying" is to find an alternative method of coating the lining of hydrodynamic bearings. The alternative methods for application of the coating could be thermal spraying or laser cladding. The coating made by these methods could have significantly better utility properties like a longer service life, ability to operate even at very high speeds, high temperatures, etc. Another, very important advantages are a shorter delivery time and saving material with using the thermal spray coating or laser cladding for repairing the lining compared to making a new bearing. [1]

In this paper, the first phase of this project is described. The optimizations for spraying the feedstock by flame and arc spray for variously materials of babbitt or aluminum bronze is described. The microstructure and a number of mechanical properties such a hardness, surface roughness or adhesion is evaluated. 
The thermal spraying is carried out in Research and Testing Institute Pilsen. The principle of thermal spray technologies is in melting of the feedstock by a heat source and then accelerating it towards the coated surface. Added material can be powder, or wires. The heat source is electrical (arc, plasma), or chemical (flame, combustion). The coating made by thermal spraying is embedded to the surface by mechanical interlocking. Thanks to that, the affection of the substrate by heating is minimal. On the other hand, the strength of this bond is lesser compared to diffusion. The thickness of the coating ranges between $20 \mu \mathrm{m}$ and a several $\mathrm{mm}$. The structure of the coating is usually laminar, heterogeneous with certain content of oxides, pores and other impurities. The using of coating depends on added materials. The main reasons for coating are thermal insulation, corrosion resistance, wear resistance, better sliding properties, dimensional restorative or an electrically resistive, to name a few. The lining of bearing is commonly coated for better sliding properties and corrosion resistance. [2]

Coating by laser cladding is made by University of West Bohemia New Technologies - Research Centre. By this method, the coating of theoretically unlimited thickness could be made. The structure of the coating is homogenous with minimum of the structural defects. Like in every cladding, the bond between the coating and substrate is on metallurgical bases. This bond is stronger than a mechanical bond, but heat affected area and residual stress is incurred. By the way, the power setting of the laser is controlled, and therefore this negative effect is minimalized.

\section{MATERIALS}

In the study, two types of adding material were tested: Tin composition and aluminum bronze.

The tin composition, called also babbitt, is an alloy based on tin or lead with cooper and antimony. This material is composed of small harder parts (antimony and copper) in a soft matrix (consisting of tin or lead). Material has excellent sliding properties and it is usually used for bearing's lining. As the bearing runs, the soft matrix is worn down and the harder part form small passages through which the lubricant can flow. Due to friction, the tin is partially melted and its lubricating properties protect the bearing from wear even in the absence of other lubricants. The feedstocks for flame spraying were powders VYN.PR1600.0895.0001 with grain $-130+50 \mu \mathrm{m}$ made by Safina, and Babtec 29240 with grain 45/125 $\mu \mathrm{m}$ made by Castolin. The powder Babtec 29240 was also used for laser cladding. For electric arc spraying, the wire Sprababbitt A was used. In the Table 1 the chemical composition of these materials is described. [3]

Table 1 Chemical composition of babbitt feedstocks

\begin{tabular}{|c|c|c|c|c|}
\hline Material & Sn & Cu & Sb & Others \\
\hline BABTEC 29240 & Balance & 3.5 & 7.5 & - \\
\hline Sprababbitt A & Balance & 3.5 & 7.5 & 0.25 \\
\hline VYN.PR1600.0895.0001 & Balance & 5 & 11 & - \\
\hline
\end{tabular}

Aluminum bronze is harder, more wear resistant and useable in higher temperature than babbitt. Thanks to aluminum the protective oxide surface is formed and it causes very good corrosion resistance. Compared to other thermal spray coatings, aluminum bronze is easily machined (but more difficult than babbitt). This material could be used for bearings, where the tin composite is insufficient, for example in bearings and pivots in satellites of wind turbines. For flame spraying the powder Cu-104-5 with grain $-125 /+45 \mu$ m made by Praxair was used. The feedstocks for arc spraying were wires CuAl7 made by Arcimplex and Sprabronze AA made by Qerlikon Metco. The chemical compositions of these materials are debscribed in Table 2. [4] 
Table 2 Chemical composition of aluminum bronze feedstocks

\begin{tabular}{|c|c|c|c|c|c|c|c|c|c|c|c|}
\hline Material & $\mathrm{Cu}$ & $\mathrm{Ag}$ & $\mathrm{Al}$ & $\mathrm{Mn}$ & $\mathrm{Fe}$ & $\mathrm{Ni}$ & $\mathbf{P}$ & $\mathrm{Pb}$ & $\mathbf{S i}$ & $\mathbf{S n}$ & Other \\
\hline Cu-104-5 & Bal. & - & 10 & - & 1 & - & - & - & - & - & - \\
\hline CuAl7 & Bal. & 0.002 & 7.64 & 0.19 & 0.008 & 0.20 & 0.003 & 0.002 & 0.007 & 0.003 & - \\
\hline Sprabronze AA & Bal. & - & 9 & - & 1 & - & - & - & - & - & 0,5 \\
\hline
\end{tabular}

\section{EXPERIMENT}

During the experiment, the optimal spraying parameters were searched. While using the flame spraying, the flows of both acetylene and oxygen and the spraying distance were varied.

During spraying babbitt by flame, the flow of acetylene was in a range from $22 \mathrm{l} / \mathrm{min}$ to $45 \mathrm{l} / \mathrm{min}$. The oxygen's flow was between $16 \mathrm{l} / \mathrm{min}$ and $40 \mathrm{l} / \mathrm{min}$. Spraying distance was in range from 135 to $230 \mathrm{~mm}$. The pressure of compressed air was 1 bar during all parameters. The feed rate of the powder was constant. During electric arc spraying, various current and pressure of compressed air were tested. The values of current were between $160 \mathrm{~A}$ and $350 \mathrm{~A}$ and the pressure of compressed air was varied from $30 \mathrm{psi}$ to $65 \mathrm{psi}$. The spraying distance was $125 \mathrm{~mm}$ and the voltage was $30 \mathrm{~V}$.

During the laser cladding, the laser power was varied between $400 \mathrm{~W}$ and $1100 \mathrm{~W}$. The feed of powder ranged from $12 \mathrm{~g} / \mathrm{min}$ to $34 \mathrm{~g} / \mathrm{min}$. The diameter of the laser beam was $3,4 \mathrm{~mm}$ and the rate was $50 \mathrm{~cm} / \mathrm{min}$.

During spraying aluminum bronze by flame, the acetylene's flow was varied from $32 \mathrm{l} / \mathrm{min}$ to $55 \mathrm{l} / \mathrm{min}$. The flowing of oxygen was changed between $27 \mathrm{l} / \mathrm{min}$ and $45 \mathrm{l} / \mathrm{min}$. The values of spraying distance were between $135 \mathrm{~mm}$ and $230 \mathrm{~mm}$. The pressure of compressed air was 1 bar during all variously parameters. The feed rate of powder was constant.

During electric arc spraying, the current was varied from $200 \mathrm{~A}$ to $350 \mathrm{~A}$ and the pressure of compressed air was from $35 \mathrm{psi}$ to $60 \mathrm{psi}$. The spraying distance was $125 \mathrm{~mm}$ and the voltage was $30 \mathrm{~V}$.

\section{METHODS OF EVALUATION}

The microstructure was evaluated on coating cross sections by optical microscope. The main evaluated factors were: profile and structure of splats, quantity and locations of unmelted particles, pores, oxide inclusion, or other impurities. The deposition rate was evaluated from coating thickness as an increment of the coating per pass. The modified method HR15Y of hardness measuring was used because of a low hardness of these coatings. The parameters of this measuring were according to a norm ČSN EN ISO 6508-1. Surface roughness was measured on as-sprayed surface by surftest Mitutoyo SJ 210.

On the bronze coating sprayed by electric arc and babbitt coating deposed by laser cladding the adhesion was also tested. On the thermal sprayed samples, the adhesion was tested according ASTM C-633. The laser cladding coating was evaluated according DIN ISO 4386-2.

\section{RESULTS}

\subsection{Babbitt}

The experiment showed that in spraying by flame, the flows of acetylene and oxygen affect the structure and characteristic of the coating very slightly, provided that the temperature of flame is not unreasonably high. The spraying distance influences the deposition efficiency. With decreasing distance the efficiency is increasing, however the residual stress in the coating is higher. 
In spraying by electric arc, the spraying parameters have a higher effect on the characteristics. The higher current brings a higher deposition rate and lower roughness. The higher pressure of compressed air causes a finer structure and slightly higher hardness.

In laser cladding the experiment showed that a higher feed rate and higher power of laser causes a porosity structure, borderline defects and low adhesion of the coating to the substrate. The structures of samples made by optimized parameters of all tested methods are shown in Figure 1.

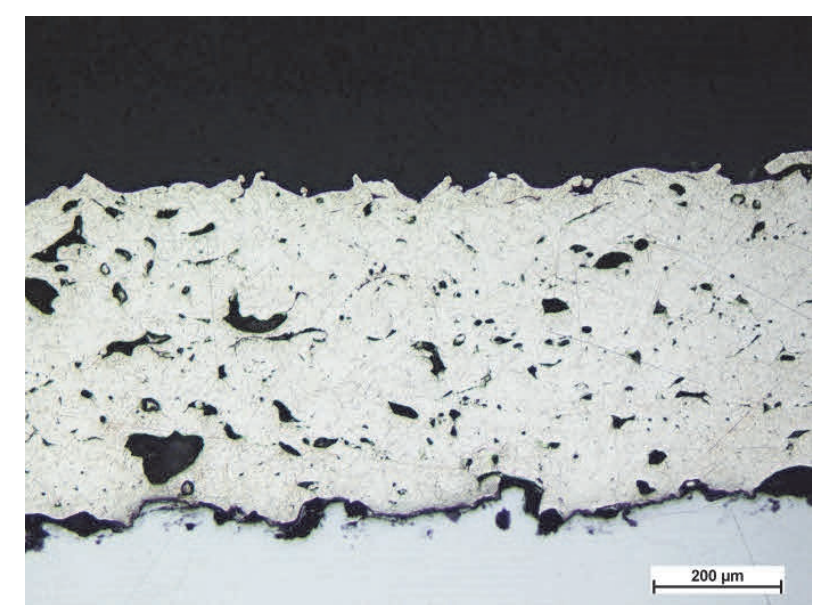

BABTEC 29240 - flame spraying

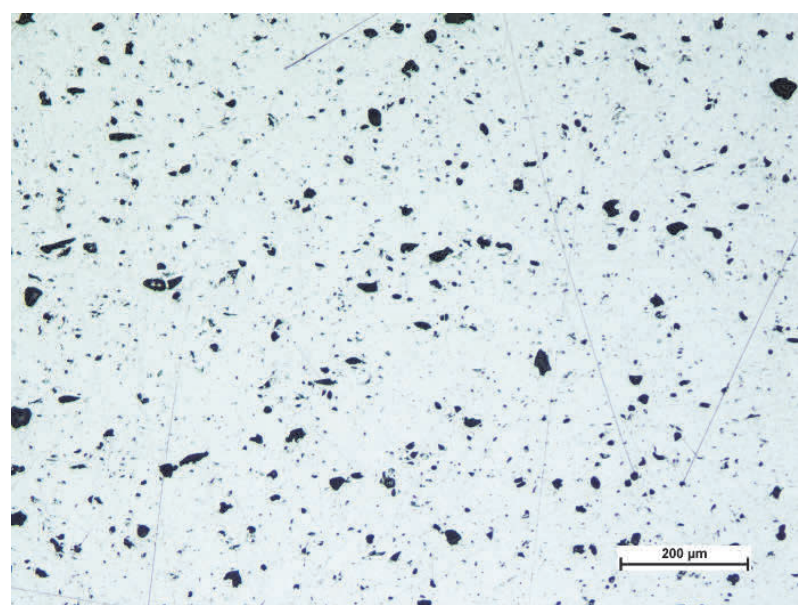

Sprababbitt A - Electric arc spraying

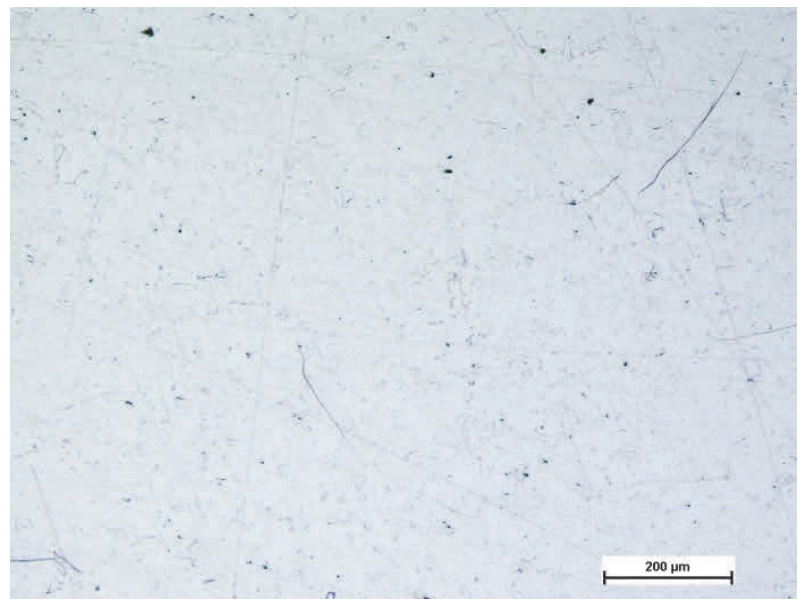

VYN.PR1600.0895.0001 - flame spraying

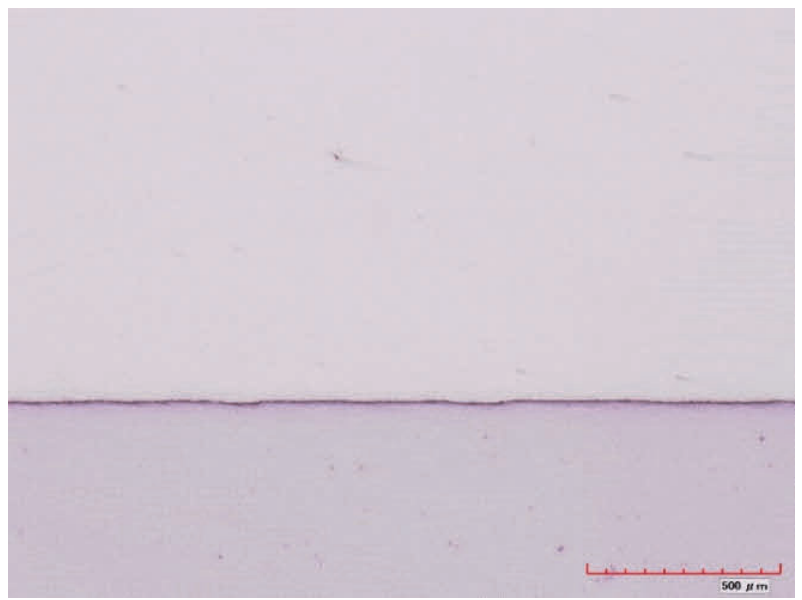

BABTEC 29240 - laser cladding

Figure 1 Microstructures of tin compositions coatings

In all of these coatings, the splats are fused very well, the boundaries between them is not recognisably. The coating made by flame with using powder Babtec 29240 and the coating made by electric arc have adequate amount of pores. The structure of coating made by laser cladding and by flame with using powder VYN.PR1600.0895.0001 was very homogenous without pores and other impurities. The hardness HR15Y of coating made by flame with feedstock Babtec 29240 was $75 \pm 3$. If the powder VYN.PR1600.0895.0001 was used, the hardness was $69 \pm 2$. The coating made by electric arc had hardness $81 \pm 4 \mathrm{HR} 15 \mathrm{Y}$.

\subsection{Aluminum bronze}

During spraying by flame, the experiment showed that with higher flows of acetylene and oxygen, the structure of coating is a slightly better with lower quantity of pores. However if the intensity of the flame is unreasonably high, some of the particles is burned. The deposition rate was affected very slightly by the spraying distance lower distance causes a higher deposition rate. 
In a spraying by electric arc the structure is affected by the pressure of compressed air. The higher value of this pressure brings a finer structure with more molded splats, lower roughness of surface and slightly higher hardness. The higher current causes a higher deposition rate. The structures of samples made by optimized parameters of the tested methods are shown in Figure 2.

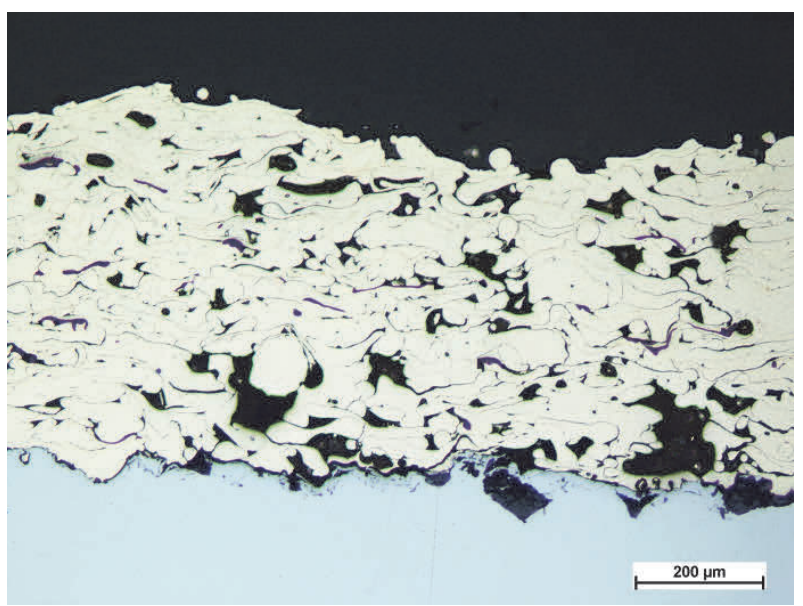

Cu-104-5 - Flame spraying

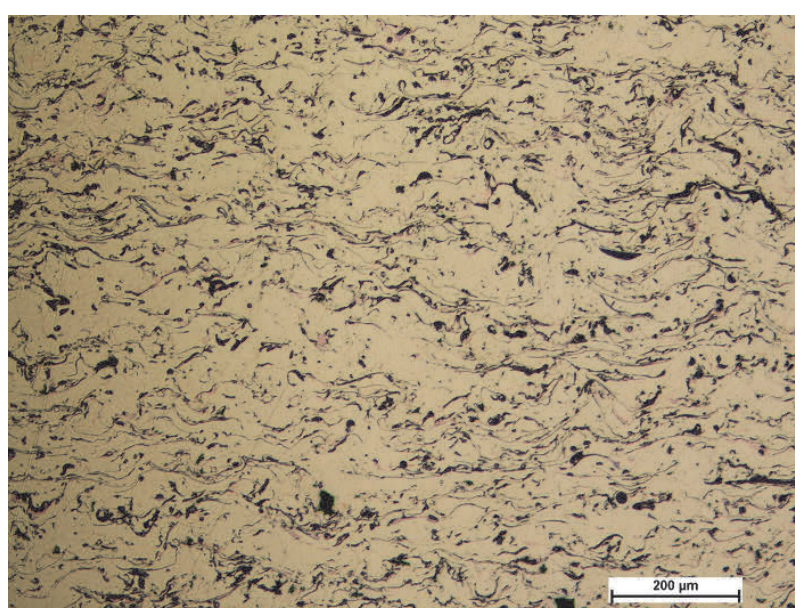

Sprabronze AA - Electric arc spraying

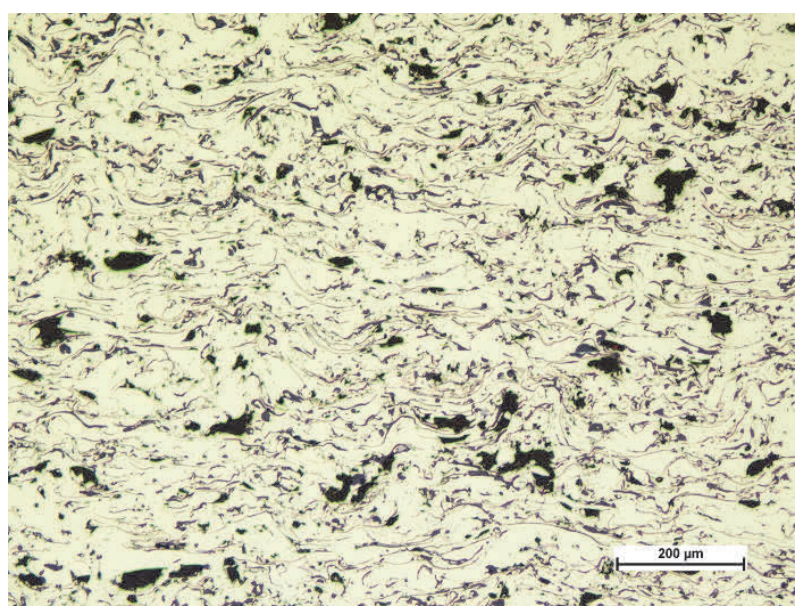

CuAl7 - Electric arc spraying

Figure 2 Microstructures of aluminum bronze coatings

The splats in coating made by electric arc are more molted and homogenous. The quantity of pores is less with using electric arc and it is also depends of used feedstock. With using the adding material with iron, the quantity of pores was minimal.

The hardness HR15Y of coating made by flame was $90 \pm 1$. The coating made by electric arc was depends on the structure of coating. The finest structure with a less pores had a higher hardness - up to 93 HR15Y for both of the feedstocks.

\subsection{Adhesion}

The samples sprayed by electric arc with feedstock CuAl7 and the coating made by laser cladding were also tested for adhesion.

The bronze coating was tested according ASTM C-633. Two types of the samples were examined - with milled grooves on the sample face under the coating and without them. During this test, the hypothesis that a larger 
contact area caused by the grooving could improve the adhesion was evaluated. The results confirm this hypothesis - the adhesion increased more than two times.

The babbitt coated by laser cladding was tested according the norm DIN ISO 4386-2. The samples were cut from the slab with coating. Capillary and ultrasound tests were performed on these samples. The capillary test didn't show any defects and the ultrasound test shown just a one small defect in adhesion near an edge of the coating.

\section{CONLUSION}

In the project "A New generation of hydrodynamic bearings with lining applicated by thermal spraying" the alternative methods of coating the lining in hydrodynamic bearing is examined. The first phase of this project is subscribed in this report. The material of coating is tin composition called babbitt and aluminum bronze. The coating was made by two methods of thermal spraying - flame and electric arc, and by laser cladding.

During the experiments the effect of spraying parameters to coating properties such a microstructure, deposition rate, hardness and surface roughness of the coatings were evaluated. The adhesion was also tested for specific coatings.

The structure of the coating depends on the method of deposition. The coating made by electric arc spraying have more homogenous and dense structure with a lower porosity compared to flame spraying (except the coating where powder VYN.PR1600.0895.0001 was used). During spraying by flame, dependency the structure of the spraying parameters was just a slight provided that the temperature of flame was not unreasonably high. If the electric arc was used, the pressure of compressed air predominantly affected the characteristic of the coating - the higher value of the pressure causes a finer structure, less quantity of pores and a higher hardness for all of tested materials. The structure and adhesion of coating made by laser cladding was affected by deposition parameters. Higher feed rate and higher power of laser brings a lower adhesion, borderline defects and higher porosity. The deposition rate was affected by value of current in electric arc spraying (higher current brings a higher deposition rate) and a spraying distance in flame spraying (lower distance brings a higher rate).

This experiment showed that all tested methods are applicable as an alternative method for coating the lining of hydrodynamic bearings. For next testing, the laser cladding such a method for coating babbitt and electric arc spraying such a method for coating the aluminum bronze were chosen.

\section{ACKNOWLEDGEMENTS}

The paper has originated in the framework of the solution of project number FV 30333 "A New generation of hydrodynamic bearings with lining applicated by thermal spraying".

\section{REFERENCES}

[1] BOBZIN, K., ÖTE, M., KÖNIGSTEIN, T., WIETHEGER, W., SCHRÖDER, T., JACOBS T. and BOSSE, D. New material concepts for thermally sprayed hydrodynamic bearings, In Proceeding of International Thermal Spray Conference ITSC 2018, Orlando, Florida, USA, May 7-10, 2018, 585 s. elSBN 978-1-62708-160-3

[2] DAVIS J., Handbook of Thermal Spray Technology. Materials Park, OH, USA: ASM International, 2004.

[3] AZIZPOUR, M. J., NOROUZI S. AND MAJD H., M. Babbitt Casting and Babbitt Spraying Processes, Case study International Journal of Mechanical and Mechatronics Engineering, Vol:5, No:8, World Academy of Science, Engineering and Technology, 2011

[4] OERLIKON METCO, DSMTS-0009.7 - Copper and Copper Alloy Thermal Spray Wires, Oerlikon Metco, 2014 